\title{
Research Paper \\ The Prediction of Children's Accident Proneness Based on Attention Deficit Hyperactivit Disorder and Sluggish Cognitive Tempo Symptoms: The Mediating Role of Sensitivity to Reward and Punishment
}

\author{
Zeinab Khanjani ${ }^{1}$, Elnaz Mohammadi*2, Mohammad Shadbafi ${ }^{3}$ \\ 1. Professor, Department of Educational Science and Psychology, Faculty of Psychology, Tabriz University, Iran \\ 2. M.A. in Clinical Child and Adolescent Psychology, Faculty of Psychology, Tabriz University, Iran \\ 3. Ph.D. Student of Psychology, Faculty of Psychology, Tabriz University, Iran
}

Citation: Khanjani Z, Mohammadi E, Shadbafi M. The prediction of children's accident proneness based on attention deficit hyperactivity disorder and sluggish cognitive tempo symptoms: the mediating role of sensitivity to reward and punishment. Quarterly Journal of Child Mental Health. 2020; 7(1): 44-56.

http://dx.doi.org/10.29252/jcmh.7.1.5

\section{A R T I C L E I N F O}

\section{Keywords:}

Attention deficit

/hyperactivity disorder, sluggish cognitive tempo, sensitivity to reward, sensitivity to punishment, accident proneness

Received: 5 Jan 2020

Accepted: 17 Mar 2020

Available: 19 May 2020

\section{A B S T R A C T}

Background and Purpose: Accidents, both intentional and unintentional, are one of the leading causes of death and disability for children around the world and impose a heavy financial burden on the health care system of societies. The aim of the present study was to predict the children's accident proneness based on attention deficit hyperactivity disorder and sluggish cognitive tempo symptoms by mediating role of sensitivity to reward and punishment.

Method: The research is descriptive and correlational. The statistical population included all elementary students of Tabriz city in the academic year of 2019-2020. For sampling, 200 students were chosen by random multistage cluster sampling method. Data were collected using Child Behavior Rating Scale (Swanson, Nolan, Pelham \& 1980), Sluggish Cognitive Tempo Questioner (Penny, Waschbusch, Klein, Corkum \& Eskes, 2009), Balloon Analogue Risk Task (Lejuez, 2002), and Minor Injury Severity Scale (Peterson, saldana \& hiblum, 1996). Data analysis was performed by path analysis using SPSS20 and AMOS 24 software.

Results: The findings show that with increasing symptoms of attention deficit / hyperactivity disorder and decreasing symptoms of sluggish cognitive tempo, the rate of accident proneness among children, increases. Also, sensitivity to reward and punishment are able to mediate the relationship between attention deficit hyperactivity disorder and sluggish cognitive tempo with accident proneness $(\mathrm{p}<0.05)$.

Conclusion: Based on these findings, it can be concluded that high sensitivity to punishment, protects children from accident proneness, because an accident is a form of punishment, and children with a high degree of sluggish cognitive tempo due to their high sensitivity to punishment, do not engage in dangerous and risky activities, so they are less likely to be injured. While children with attention deficit hyperactivity disorder are always at risk because of their high sensitivity to rewards, so they are more likely to be injured.

\footnotetext{
* Corresponding author: Elnaz Mohammadi, M.A. in Clinical Child and Adolescent Psychology, Faculty of Psychology, Tabriz University, Iran. E-mail addresses: Mohammadielnaz94@yahoo.com
} 


\section{يِيشينى سانحه يذيرى كود كان بر اساس نشانهاى نارسايى اختلال توجه- فزون كنشى و كند كامى شناختى: نقش ميانجى حساسيت به ياداش و تنبيه

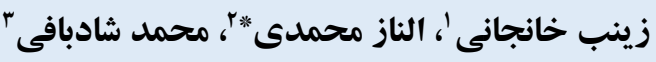

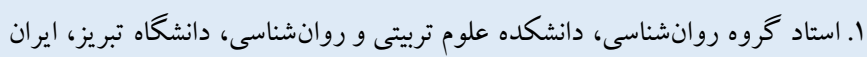

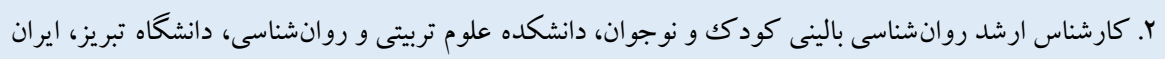

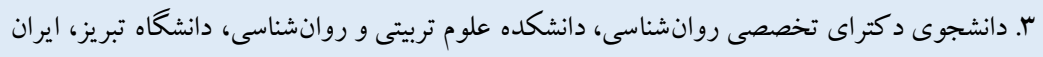

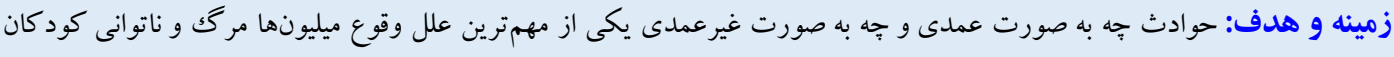

مشخصات مقاله

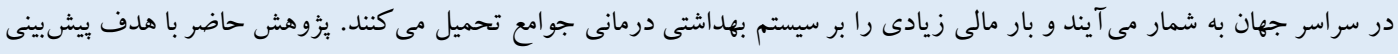

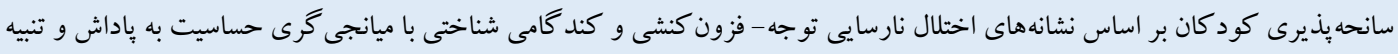

انجام شد.

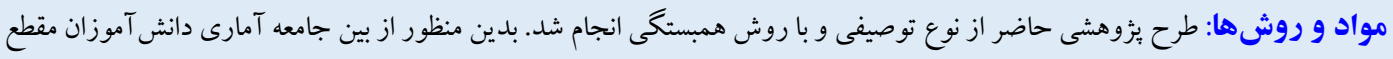

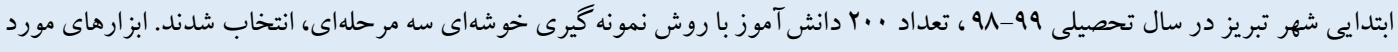

كليدوازهها:

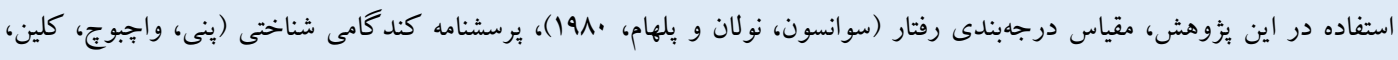

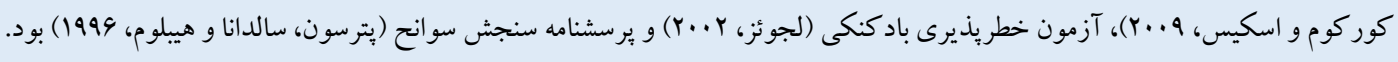

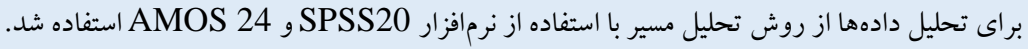

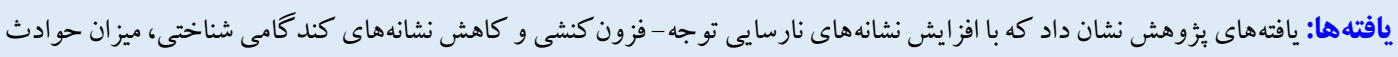

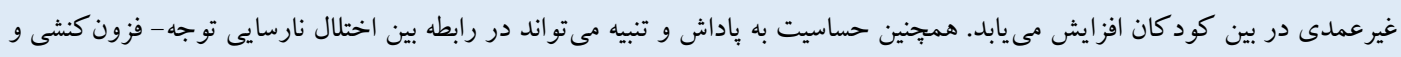

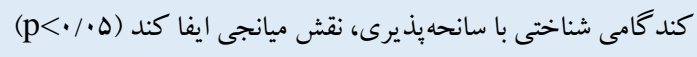

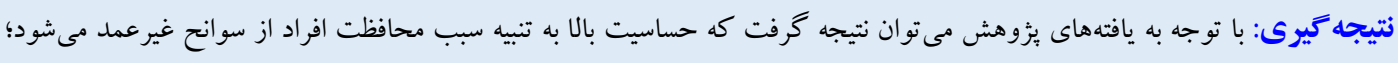

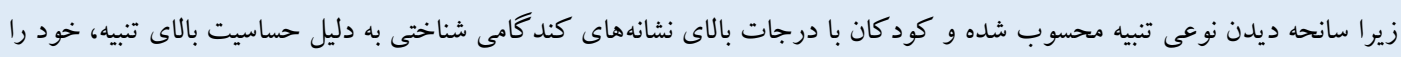

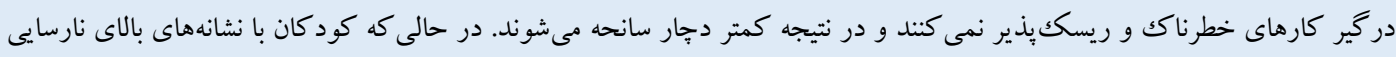

دريافت شده:

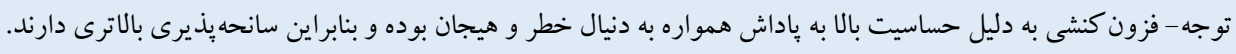

* نويسنده مسئول: الناز محمدى، كارشناس ارشد روانشناسى بالينى كودك و نوجوان، دانشكده علوم تربيتى و روانشناسى، دانشكاه تبر يز، ايران.

رايانامه:yahoo.com 
محر ككهـاى نـامربوط، تعريف مىشــود (ه). براى مثـال ممكن اســت

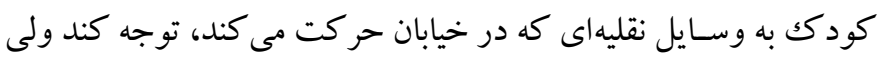

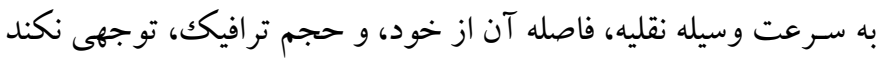

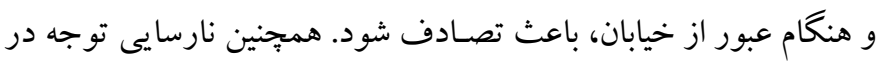

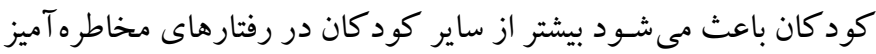

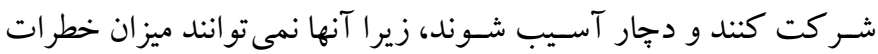

محيطى و ميزان توانايى خود در رويارويى با خطر را بر آورد كنند (9).

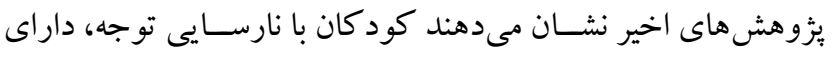

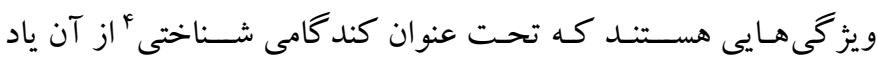

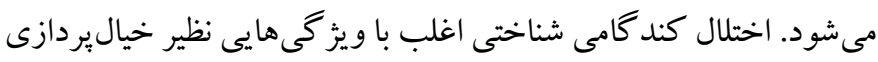
بيش ازحد، سردر گمى ذهنى، تفكر و رفتار آهسته، بى حالى، بى تفاوتى، و و

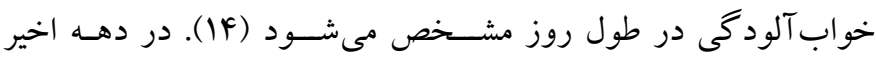

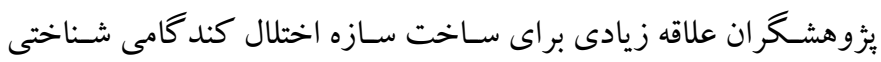

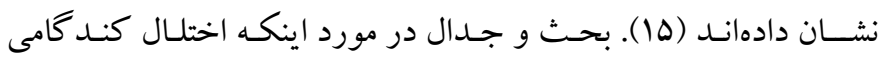

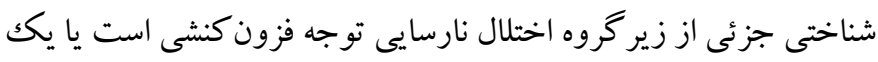

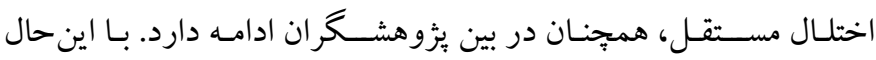

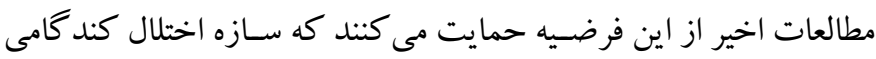

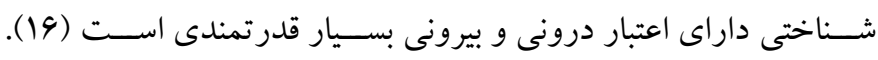

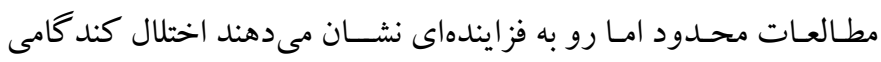

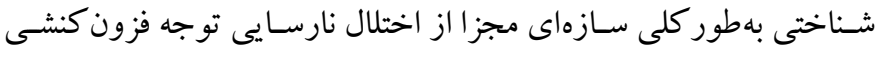
اسـت كه با عملكرد ضـعيف تر و نقايص بيشـترى همر اه اسـت (IV).

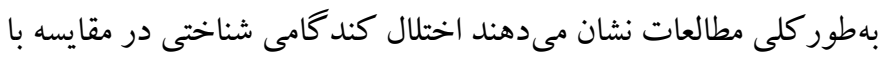

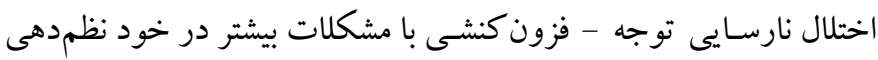

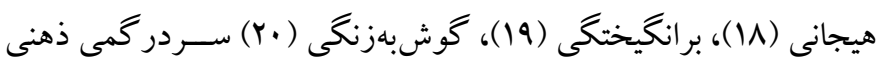

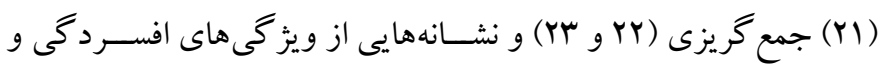

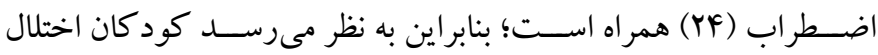

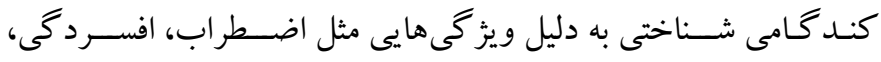

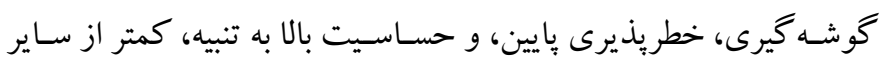
كود كان دجار سانحه و آسيب شوند.

3. Adjustment Ability

4. Sluggish cognitive tempo (SCT)
مقلدمه بيانيه حقوق كودكك كه تقريباً به تأييد تمامى دولتها رسـيده، بيان

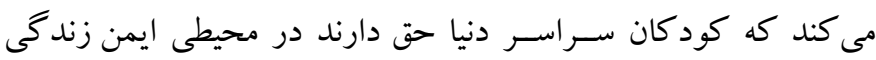

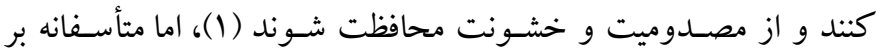
اسـاس گزارش مشـتر كك سـازمان سـلامت جهانى و صــدوق كود كان

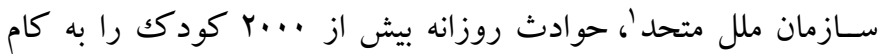

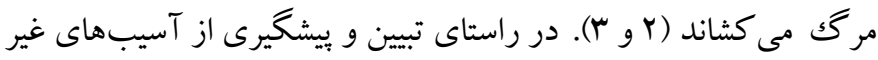

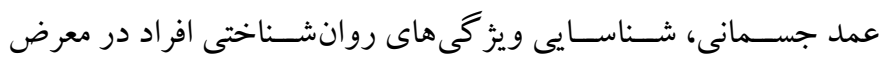

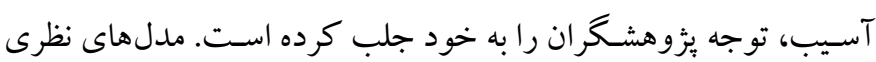

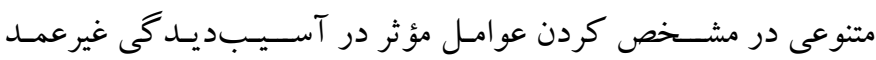

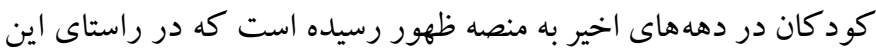

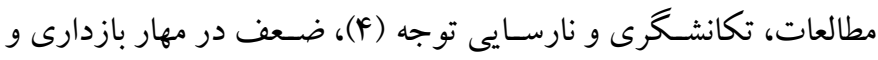

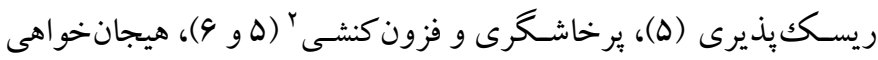

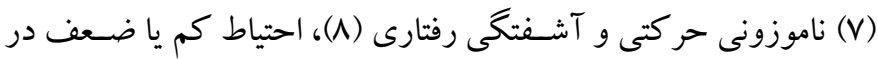

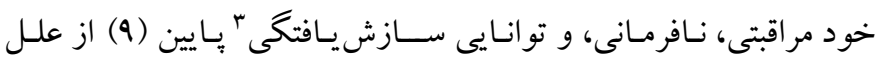
آسيبديدكى غير عمد كود كان در نظر كرفته شدهاند.

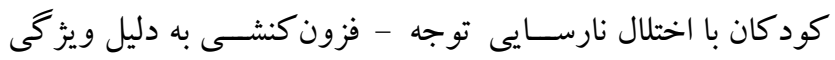
هيجان خو اهى، رفتار هاى غيرقابل مهار، و ريسكك يذّيرى و حساسيت بالنا نسـبت به ياداش در مقايسـه با كود كان بهنجار، بيشـتر در معرض سـوانح عمدى و غيرعمدى هستند ( •او (1). يكى از مهم ترين ويز گیى هاى اين

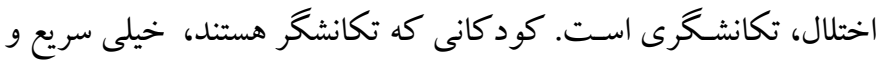
بدون فكر واكنش نشــان مىدهند؛ يعنى بدون اينكه احتمال بيامد ناكوار

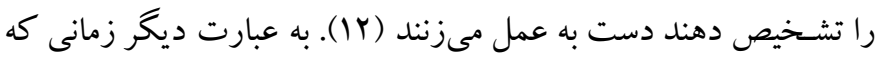

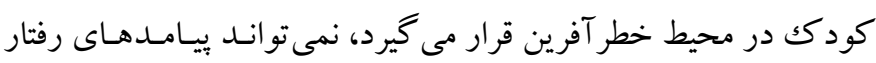

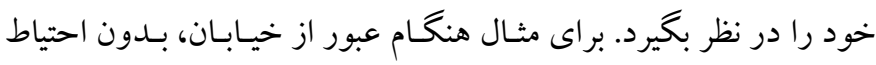
عبور مى كنـد و اين احتمـال را نمىدهد كه در صــورت عبور از خهيابان

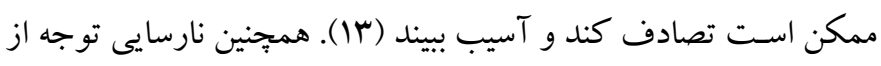

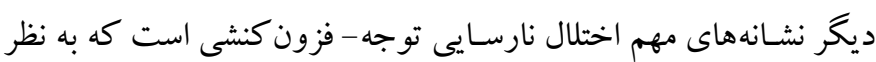

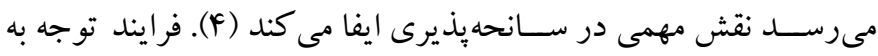

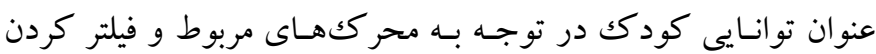

1. United Nations International Children's Emergency Fund (UNICEF)

2. Hyperactivity 
نمى توانند رفتارهاى خود را تنظيم كرده و از بسـخوراندهاى موجود بهره

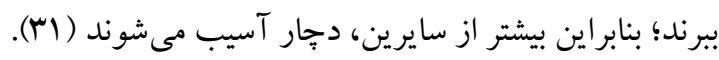

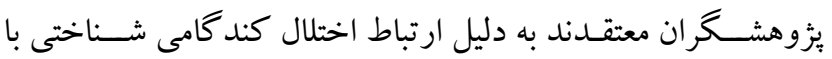

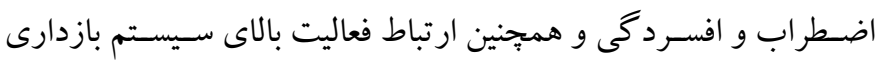

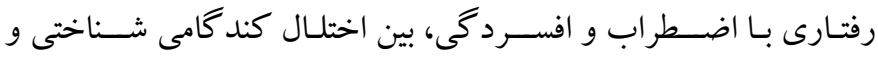

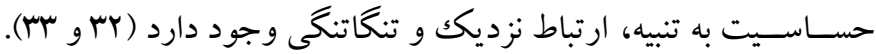

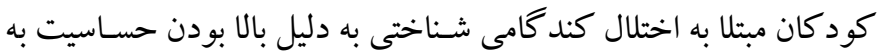

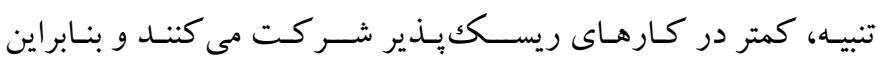

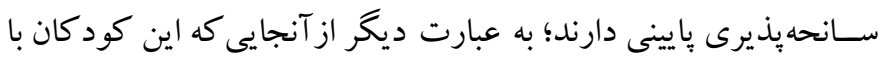

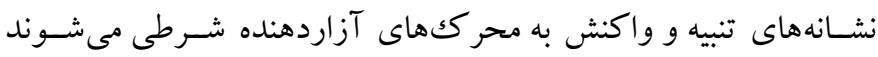
هر كاه در حين انجام فعاليتى دجار سـانحه مى شوند، نسبت به آن موقعيت و شـر ايط مسـبب آسـيب، شـرطى شــده و هنگام مواجهه دوباره با آن

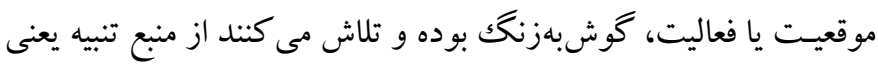
سانحه دور بمانند (FF (MF).

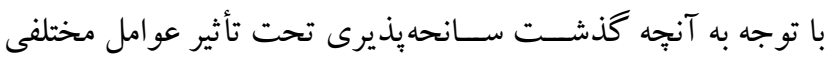

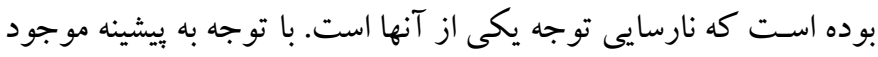

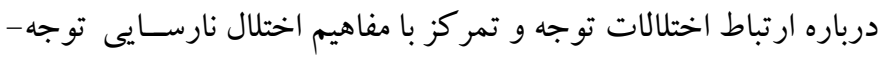

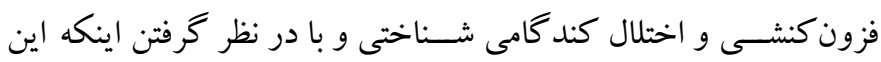
عوامل نيز خود از متغيرهاى ديخرى مانند حساسيت به پياداش و حساسيت

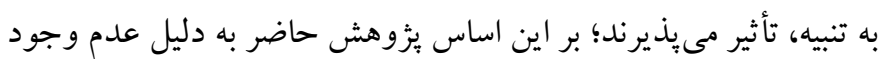

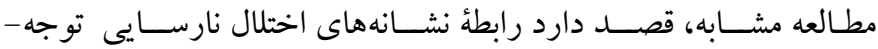
فزون كنشسى و اختلال كند كامى شـناختى را بر روى سـانحه يذيرى و از

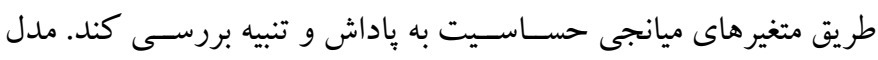
مفهومى يثزوهش به صورت زير است:
در بررسى عوامل شخصـيتى، بررسى بعل زيستى - عصبى شخصيت

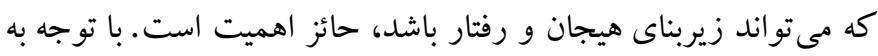

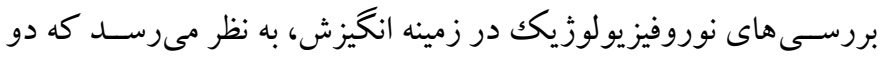

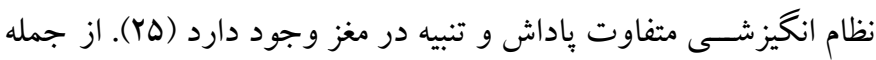

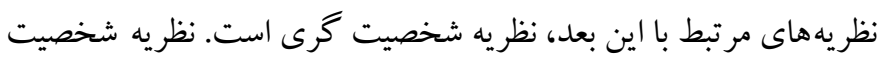
كرى كه نظريه حساسيت به تقويت نيز ناميده مىشود سه سيستم مغزى -

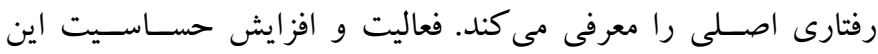

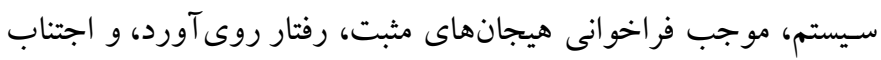

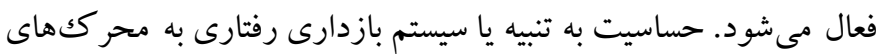
شــرطى تنبيـه و فقـدان پـاداش و همجِنين بـه محرك هاى جديد و محر ككهاى ترس آور ذاتى، باسـخ مىدهد. فعاليت اين سيستم موجب

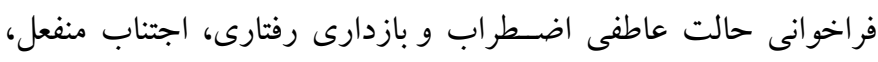
خاموشى، و افزايش توجه مىشود. سومين سيستم، سيستم جنگك وكريز و بهت اسـت كه به محرك كهاى ناخوشـايند (شرطى و غيرشرطى)، باسخ مىدهد (Y) (Y). مطالعات نشـان مىدهد كود كان با اختلال نارسايى توجه/فزون كنشى

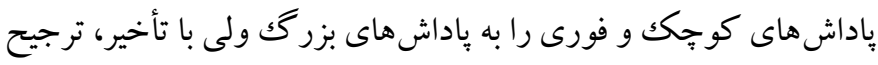

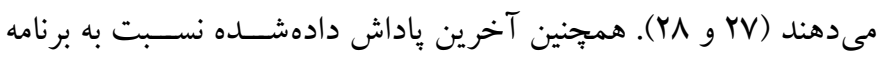

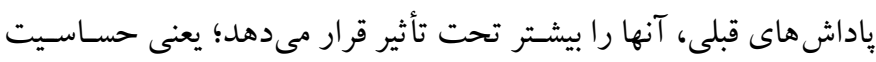

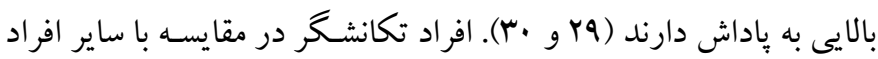

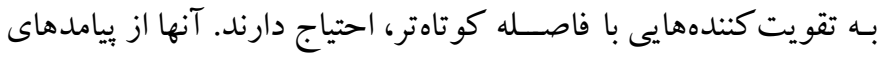
رفتـار خود تجربـه كســب نمى كنتـل و حتى يس از تنبيه شـــن، دوباره

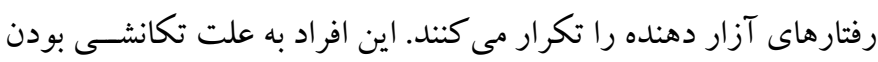

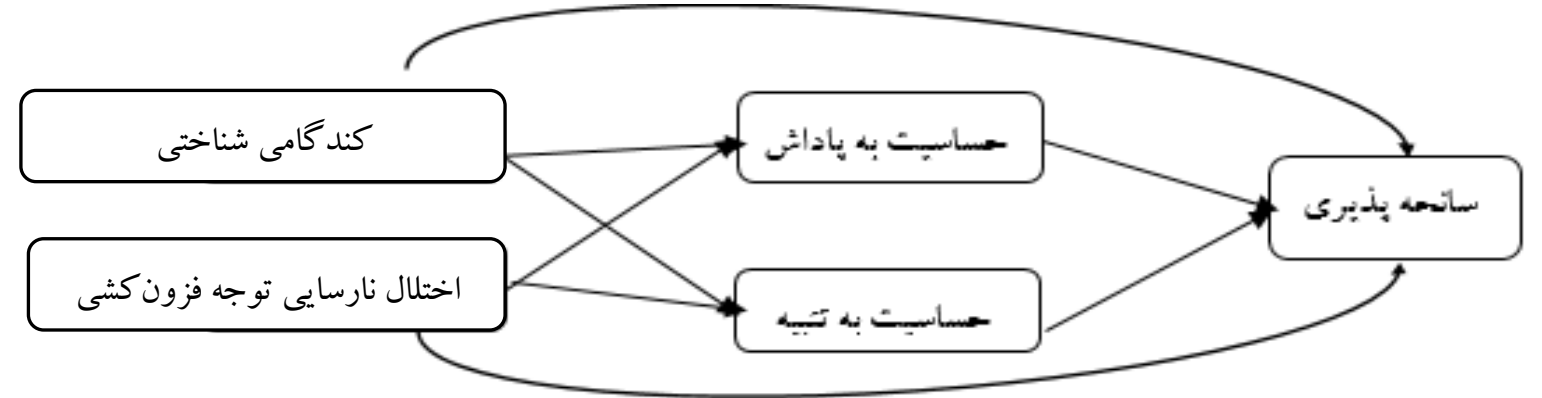

شكل 1: مدل مفهومى يخوهش 
بررسـى بايايى اين آزمون از طريق باز آزمايى با فاصسله زمانى Y هفته

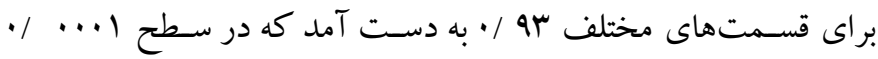

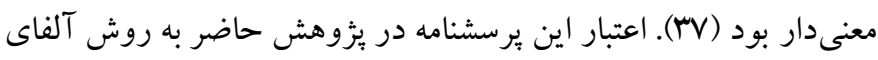
كرونباخ 191/ به دست آمد. r. مقياس درجهبندى (فرم والد)": اين آزمون اولين بار توسط سوانسون، نولان و بلهام، در سـال • •191 و بر اسـاس نشـانهاى اختلال در راهنماى آمارى و تشـخيصى اختلال هاى روانى ساخته شد. بر اساس ويرايشهاى

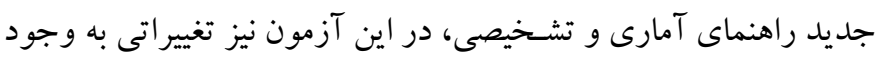

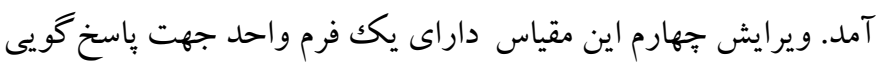

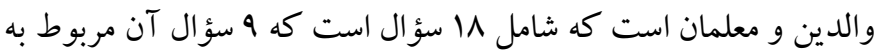
زير مقياس نارسـايى توجه و 9 سـؤوال مربوط به زير مقياس فزون كنشسى /

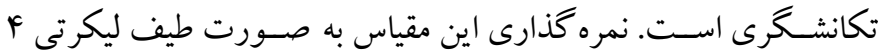

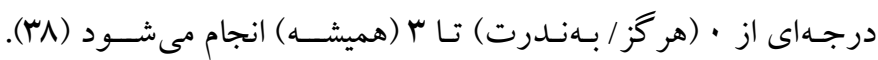

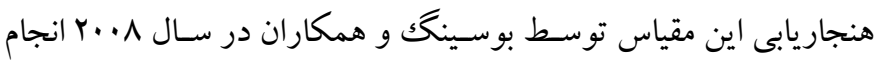

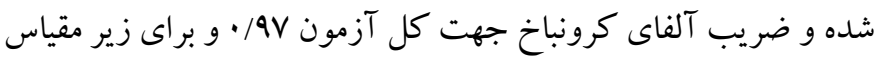

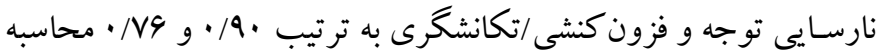

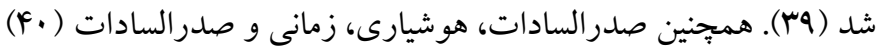

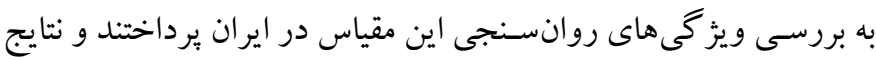

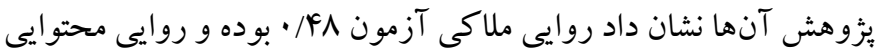

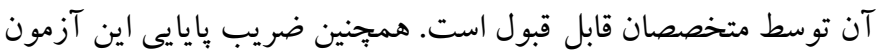

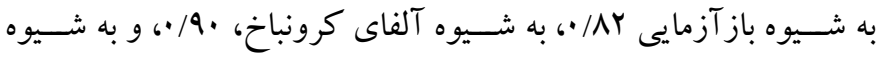

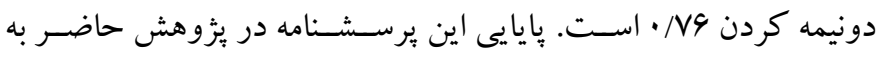
روش آلفاى كرونباخ V9/ • به دست آمد.

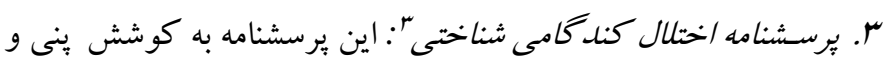

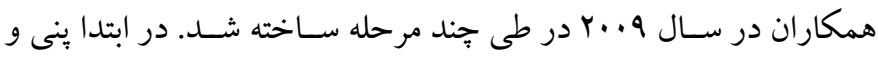

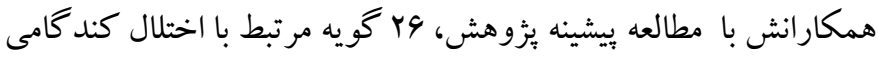

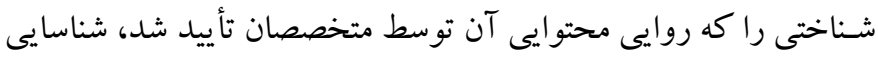

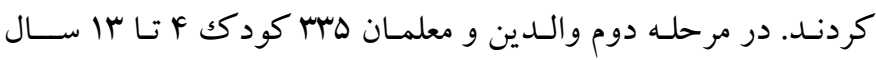
ير سـشنامه צY گويهاى را تكميل كردند. در مرحله سوم با محاسبه تحليل

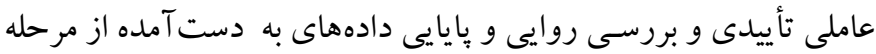

روش ثزوهش

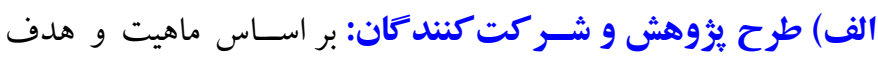

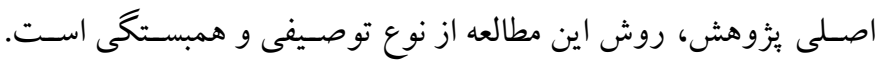

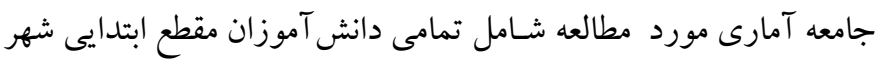

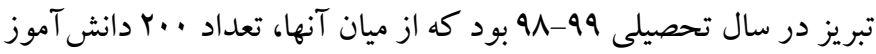

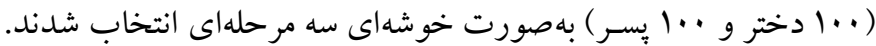
لازم به ذكر است كه معيار انتخاب اين حجم نمونه، رعايت شرط حداقل

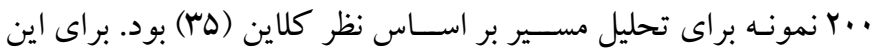

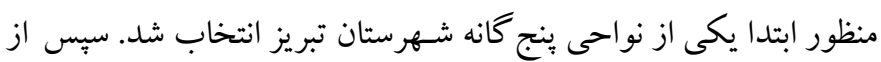

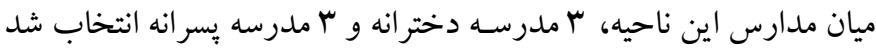

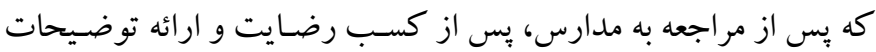

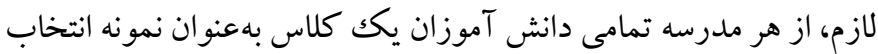

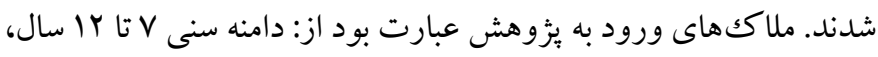

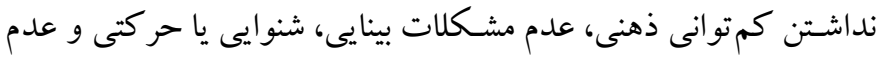

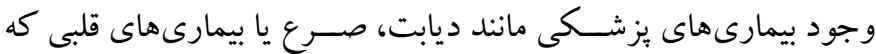

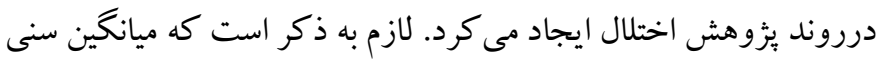

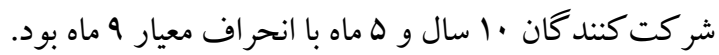

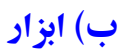
1. مقياس آسـيبديدكى غيرعمل ': اين مقياس در سـال 1999 توســط

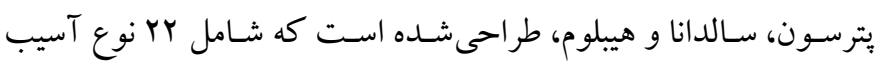

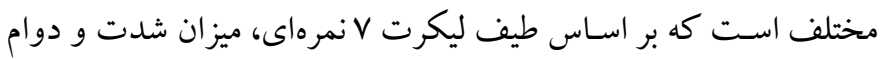
آسيب توسط كودك،، نمره گذارى مىشود. بايايى اين آزمون از طريق

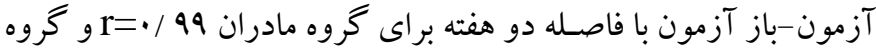

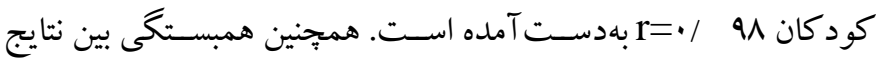

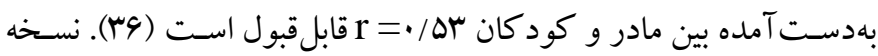

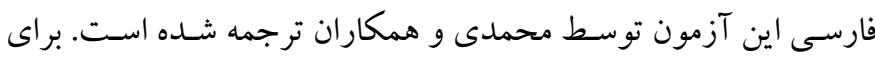
بررسى روايى اين يرسشـنامه از روش روايى صورى و محتو ايى استفاده

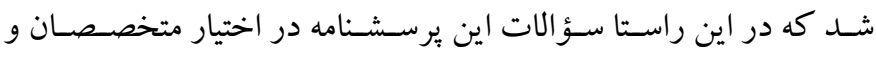
روانشـاسـان قرار داده شد كه به طور حداكثرى، مفاهيم موجود در اين

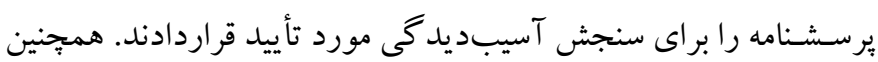


رضـايت و ارائه توضيحات للازم، از هر مدرسه تمامى دانش آموزان يكك كلاس به عنوان نمونه انتخاب شدند. للازم به ذكر است كه تمام ملاحظات

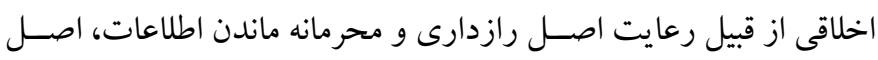

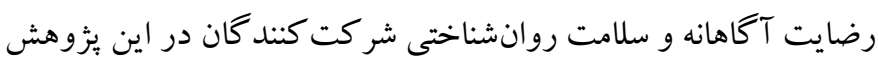

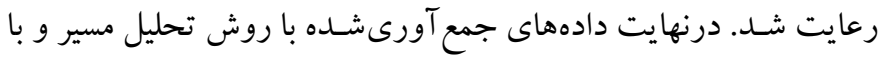
استفاده از نرمافزارهاى SPSS و 20 و AMOS 24 تحليل شدند.

\section{يافته ها}

در جدول ا شـاخصهاى توصسيفى متغيرها شـامل ميانخين، انحراف

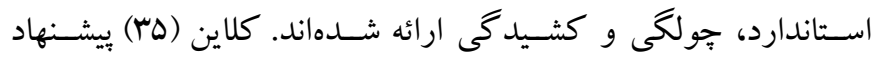

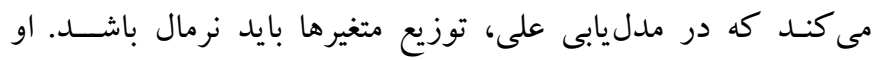

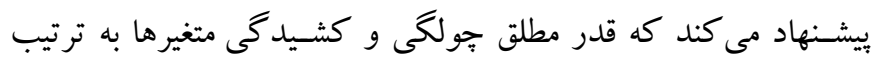

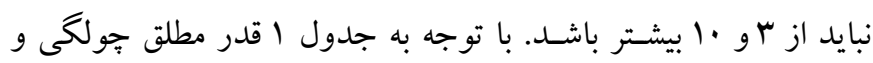

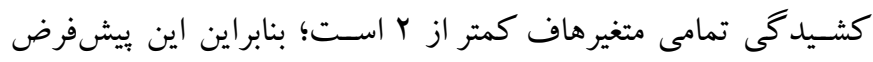
مدل يابى على يعنى نرمال بودن تككتغيرى برقرار است.

جدول ا: يافتهاى توصيفى مربوط به متغيرها

\begin{tabular}{|c|c|c|c|c|}
\hline كشيدكى & جولكى & استحراف افدارد & ميانتين & متغير /شاخص \\
\hline$-1 / Y \Lambda$ &.$/ 10$ & $|f / A|$ & TV/GY & نارسايى توجه-فزون كنشى \\
\hline$-1 / \Delta \Delta$ &.$- / .1$ & $1 \Delta / \Delta \Lambda$ & rG/Tr & كند كامى شناختى \\
\hline.$/ \cdot 1$ & $\cdot / A r$ & 1.199 & 9/9. & حساسيت به پاداش \\
\hline.$/ 4$ & $\cdot / \mathrm{NI}$ & IY/AV & $r \mu / \Delta q$ & حساسيت به تنبيه \\
\hline$\cdot / 4 \wedge$ &.$/ 99$ & IV/YT & $\mathrm{rM/ \Lambda}$ & سانحه يذيرى \\
\hline
\end{tabular}

در جدول r ماتريس همبسـتخى متغيرهاى يزوهش ارائه شـدهاند. بر

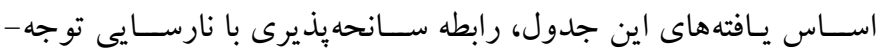

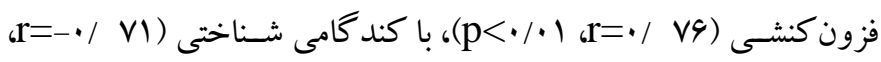

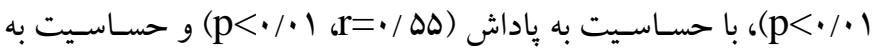

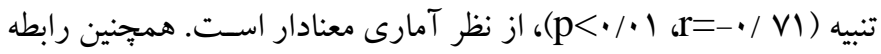

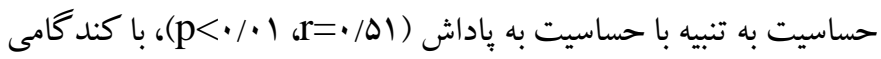

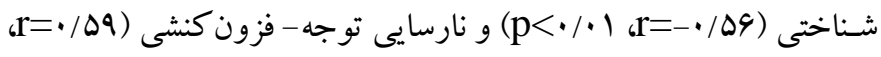

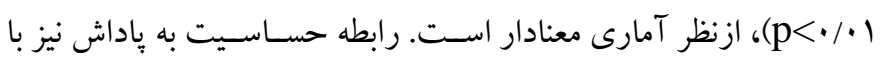

3. Daydreamer

4. Balloon Analogue Risk Task

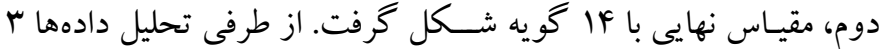

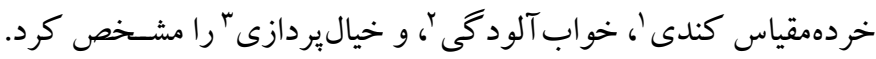

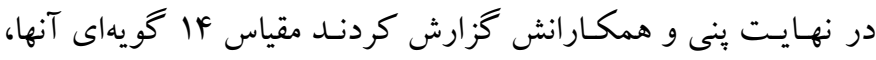
روايى محتوايى مطلوب، همسانى درونى قابل قبول، و يايايى آزمون- باز

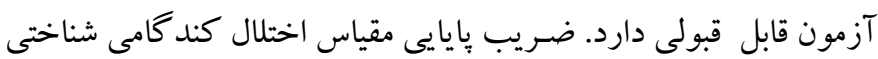

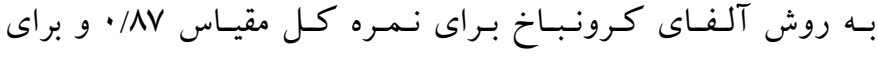

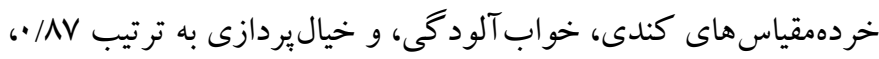

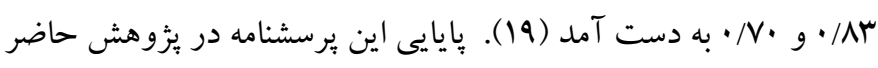
به روش آلفاى كرونباخ rAr/ • به دست آمد.

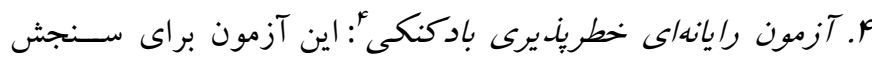

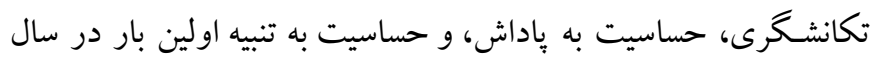

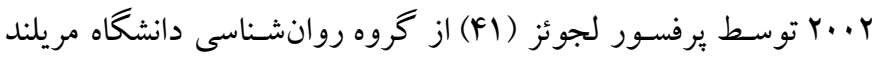

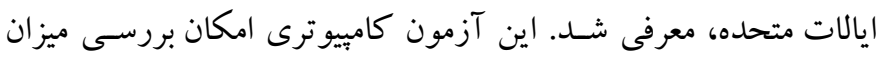

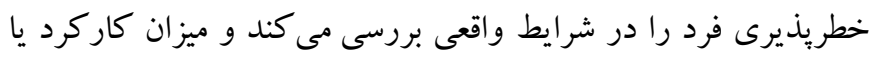

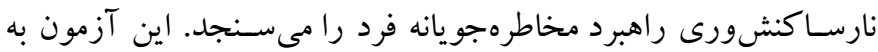
كونهاى طراحى شــده اسـت كه درجات اوليه خطريذيرى آزمودنى، سودبخش و همراه با باداش؛ و خطريذيرى مهار نشده او با ضرر همراه

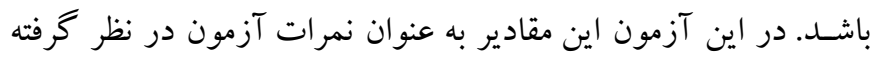

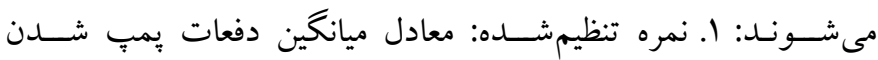
بادكنككهايى اسـت كه نتر كيدهاند. اين متغير، نمره اصسلى آزمون و شـاخص خطريذيرى و تكانشگرى آزمودنى است؛ ז. نمره تنظيم نشده:

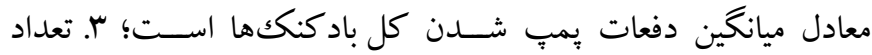

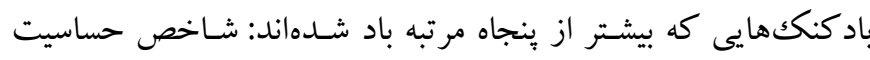

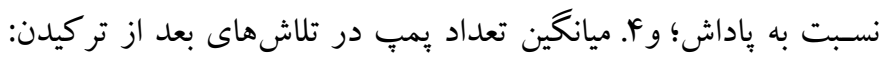
شاخص حساسيت منفى نسبت به تنبيه (FY). ج) روش اجرا: بِ از اخـذ معرفى نـامـهـ از دانشــكـده علوم تربيتى و

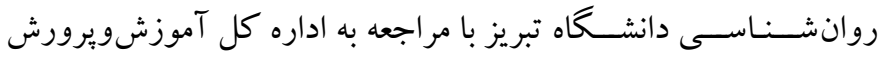

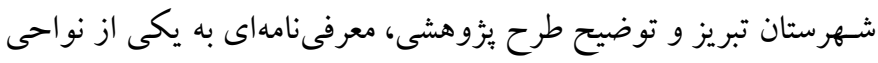

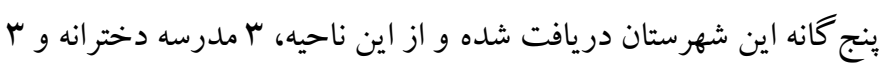

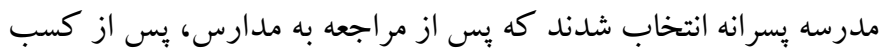


تطبيقى ^، شاخص برازش هنجار شده^، شاخص برازش هنجار نشده به عنوان شـاخصهاى برازش تطبيقى؛ و مجذور خى بر درجه آزادى

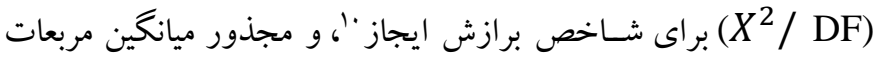

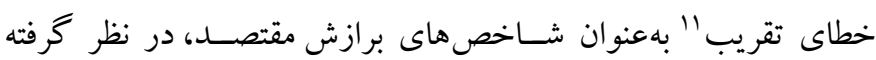

\begin{tabular}{|c|c|c|c|}
\hline \multicolumn{4}{|c|}{ شاخصهاى برازش مطلق } \\
\hline SRMR & AGFI & GFI & شاخص \\
\hline.$/ \cdots$ &.$/ 90$ &.$/ 99$ & مقدار بهدست آمده \\
\hline \multicolumn{4}{|c|}{ شاخصهاى برازش تطبيقى } \\
\hline NNFI & NFI & CFI & شاخص \\
\hline.$/ 99$ &.$/ 99$ &.$/ 99$ & مقدار بهدست آمده \\
\hline \multicolumn{4}{|c|}{ شاخص هاى برازش تعديل يافته } \\
\hline RMSEA & PNFI & $X^{2} / \mathrm{DF}$ & 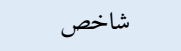 \\
\hline.$/ . \Delta$ &.$/ 1$ & $1 / 94$ & مقدار بهدست آمده \\
\hline كمتر از ^•• & بيشتر از •19/. & كمتر از ب ك ك & حد قابل يذيرش \\
\hline
\end{tabular}

در جدول ب مقادير به دست آمده در يثزوهش حاضربراى هر يكك از

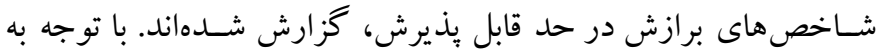

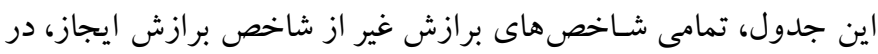

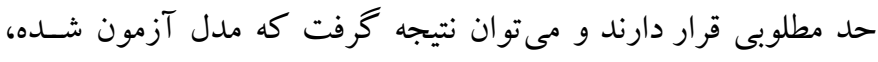

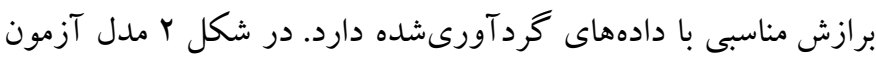
شده يزٔوهش نشان داده شده است.

7. Comparative Fit Index

8. Normed Fit Index

9. Non- Normed Fit Index

10. Parsimony Fit Index

11. Root Mean Square Error of Approximation

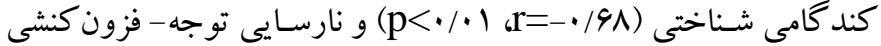

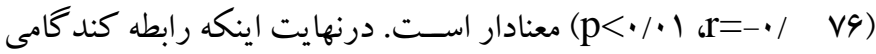

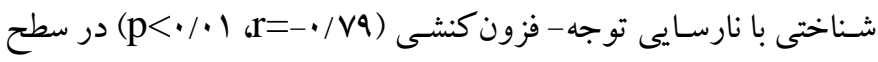

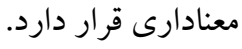

\begin{tabular}{|c|c|c|c|c|c|}
\hline \multirow[t]{5}{*}{0} & $\varepsilon$ & $r$ & $r$ & 1 & متغير /شاخص \\
\hline & & & & 1 & نارسايى توجه- فزون كنشى \\
\hline & & & 1 & $-\cdot / \vee 9 * *$ & كند كامى شناختى \\
\hline & & 1 & $-\cdot / 9 \wedge * *$ & $\cdot / v 9 * *$ & حساسيت به پِاداش \\
\hline & 1 & $\cdot / \Delta 1 * *$ & $-\cdot / \Delta 9 * *$ & $\cdot / \Delta ৭ * *$ & حساسيت به تنبيه \\
\hline 1 & $\cdot / N \mid * *$ & $\cdot / \Delta \Delta * *$ & $-\cdot / \mathrm{V} \mid * *$ & $\cdot / \sqrt{ } 9 * *$ & سانحه يذيرى \\
\hline
\end{tabular}

در ادامه از روش بيشـينه احتمال براى آزمون الكوى نظرى يزوهش

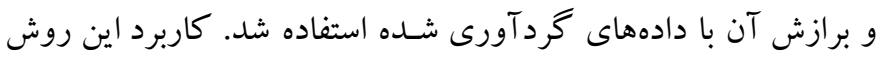
نيازمند نرمال بودن جند متغيره متغيرها اسـت. براى بررسى نرمال بودن

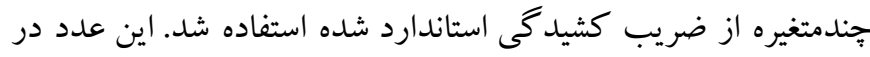

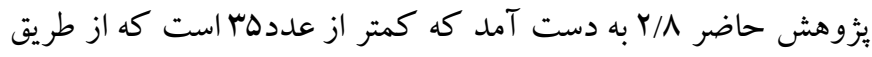

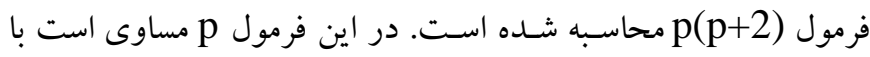

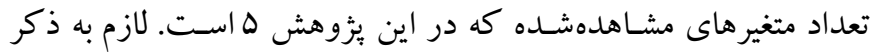
اسـت كه از نرمافزار ايموس نسخه 24 براى تجزيه تحليل اين دادهها |ستفاده شد.

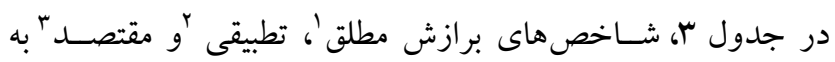

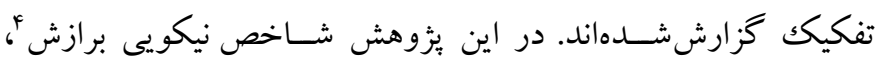
شاخص نيكويى برازش تعديل يافته، و ريشه ميانگين مربعات باقيمانده

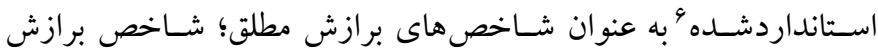

1. Absolute

2. Comparative

3. Parsimonious

4. Goodness of Fit Index

5. Adjusted Goodness of Fit Index

6. Standardized Root Mean Squared Residual 


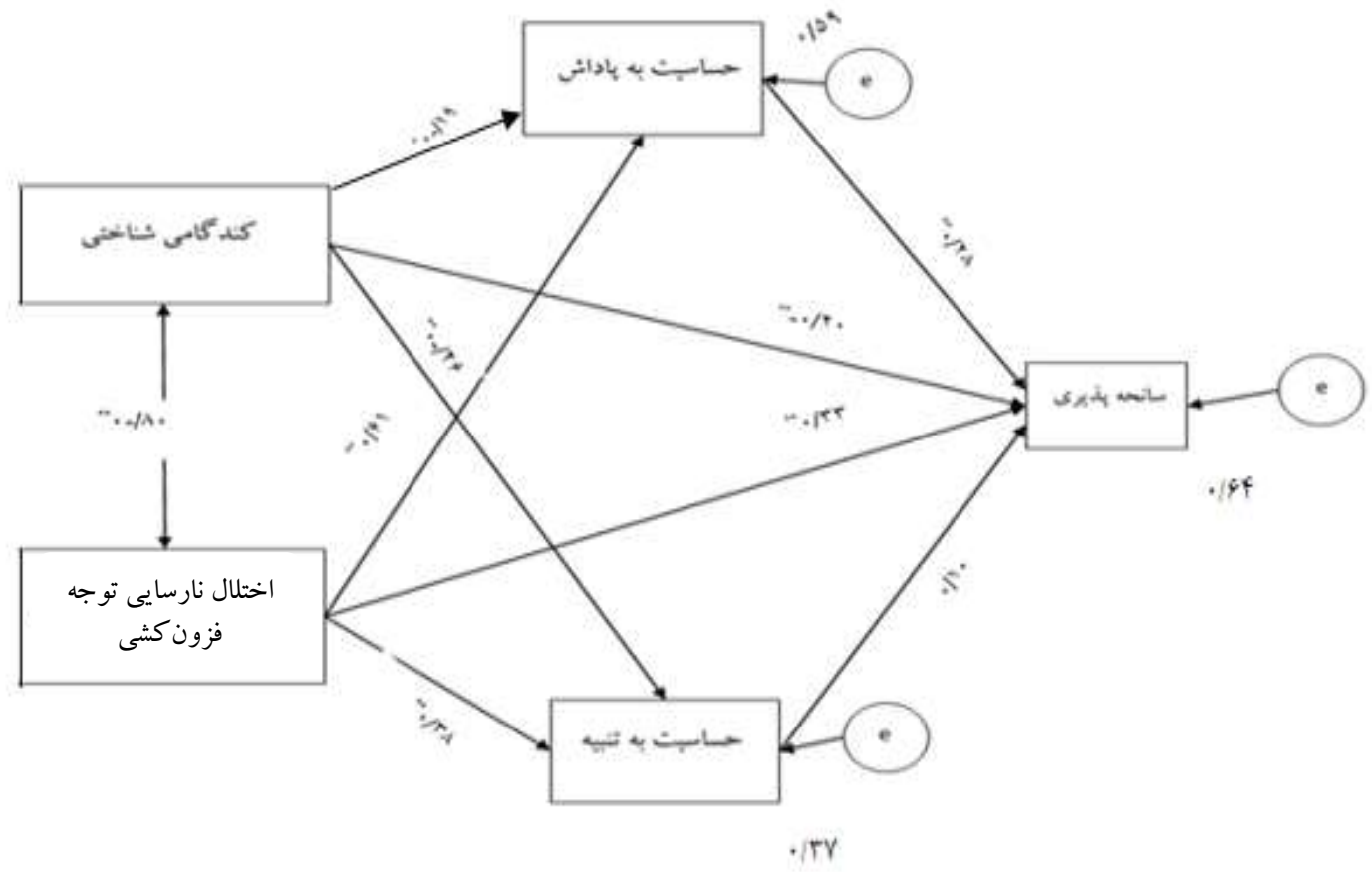

شكل r: الكوى آزمون شده يزوهش

مندرجـات جـدول f نشــان مى دهد اثر مســتقيم نارسـايى توجه-

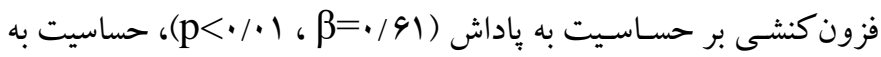

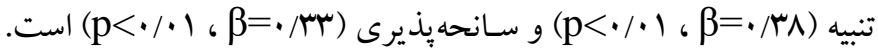

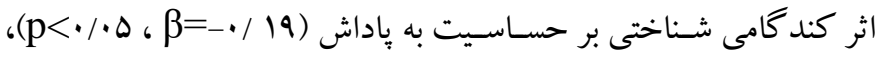

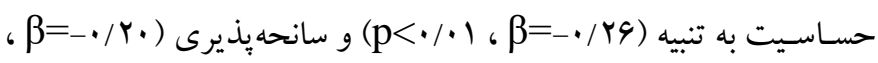

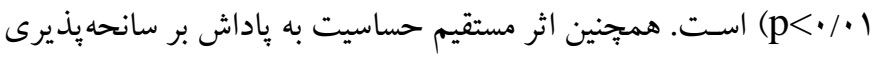

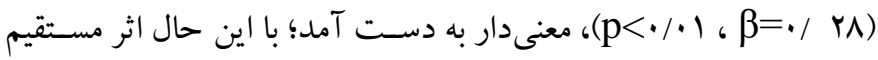

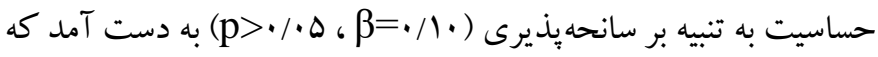
معنى دار نيست. علاوه بر اين جهت بررسى اثرات غيرمستقيم از روش بوت اسـتراب استفاده شد. بوت استراب در برنامه AMOS توزيع نمونه گيرى بر آورد برد

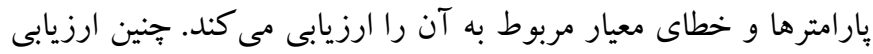

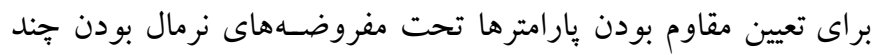

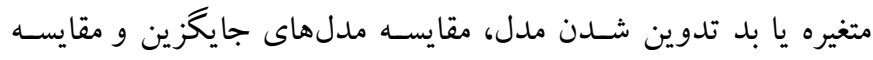

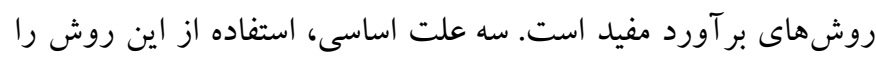
در مطالعه حاضر توجيه مى كند. نخست اينكه در آزمون سوبل، مشكل
با توجه به شـكل r، نارسايى توجه - فزون كنشى، كند گامى شناختى،

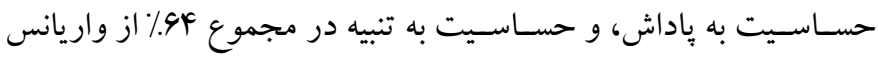

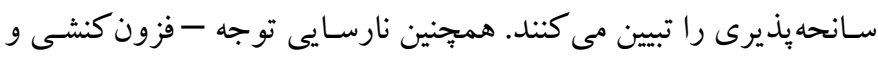

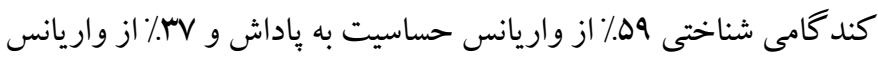

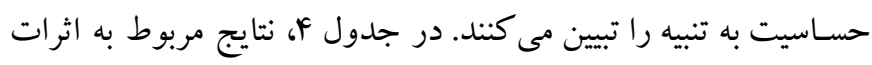
مستقيم متغيرها كزارش شده است.

\begin{tabular}{|c|c|c|c|c|}
\hline معنى دارى & $\mathbf{T}$ & مقدار & متغير وابسته & متغير مستقل \\
\hline.$/ . .1$ & $\Lambda / \cdot V$ & .191 & حساسيت به ياداش & نارسايى توجه- فزون كنشى \\
\hline.$/ .1$ & $r / \cdot r$ & $\cdot / \mu_{\Lambda}$ & حساسيت به تنبيه & نارسايى توجه- فزون كنشى \\
\hline.$/ . .1$ & r/q9 & 每/ & سانحهذيرى & نارسايى توجه- فزون كنشى \\
\hline.$/ 11$ & $-Y / \Delta F$ &.$- / 19$ & حساسيت به باداش & كند گامى شناختى \\
\hline.$/ . \Delta$ & $-Y / A$. & $-\cdot / 49$ & حساسيت به تنبيه & كند كامى شناختى \\
\hline $.1 . .4$ & $-Y / N F$ & $-\cdot / r$ & سانحهذيذيرى & كند گامى شناختى \\
\hline.$/ . .1$ & $F / 1 \Lambda$ & $\cdot / r \wedge$ & سانحهيذيرى & حساسيت به باداش \\
\hline .1 .94 & $I / A V$ & $\cdot /$ & سانحهيذيرى & حساسيت به تنبيه \\
\hline
\end{tabular}


كرفتن دادههاى نمونهاى مجدد و يا اعتبار متقاطع با دونيمه كردن

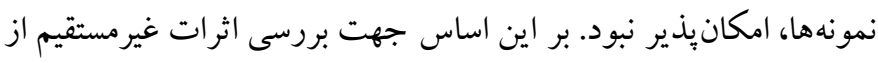

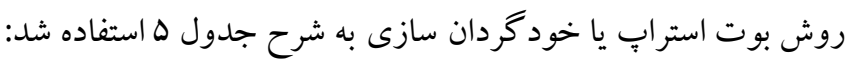

مربوط به توزيع غيرنرمال اثر غيرمسـتقيم نمونه وجود دارد و جون

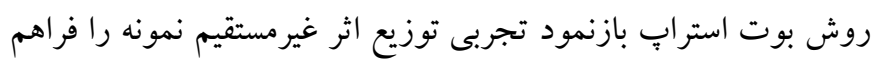

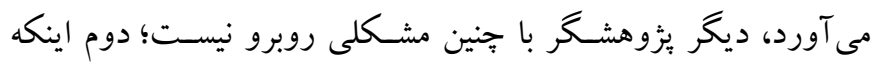
روش بوت اسـتراب، توان آمارى بيشـترى دارد؛ و سـوم اينكه امكان

جدول 0: اثرات غير مستقيم با استفاده از روش بوت استراب

\begin{tabular}{|c|c|c|c|c|c|c|}
\hline \multirow{2}{*}{ سطح معنىدارى } & \multirow{2}{*}{ مقدار اثر } & \multicolumn{2}{|c|}{ حدود بوت استراب } & \multirow{2}{*}{ متغير وابسته } & \multirow{2}{*}{ متغير ميانجى } & \multirow{2}{*}{ متغير مستقل } \\
\hline & & حد هايين & حد بالا & & & \\
\hline.$/ \cdot 1$ & $\cdot /$ VV & $\cdot / 1$. & $\cdot / 490$ & سانحه يذيرى & حساسيت به پاداش & نارسايى توجه- فزون كنشى \\
\hline$\%$ ro & $.1 .4 \Delta$ &.$/ \cdot 1 r$ & .1 .90 & سانحهيذيرى & حساسيت به تنبيه & نارسايى توجه- فزون كنشى \\
\hline 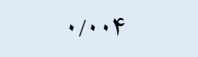 & $-\cdot / \cdot \Delta \Delta$ & $-\cdot / 1 \cdot 1$ & $-\cdot / \cdot r r$ & سانحه يذيرى & حساسيت به پاداش & كند كامى \\
\hline$\cdot / \mathrm{rA}^{\prime}$ & $-\cdot / \cdot \mu_{1}$ & $-\cdot / \cdot V F$ & $-\cdot / \cdot \cdot v$ & سانحهيذيرى & حساسيت به تنبيه & كند گامى شناختى \\
\hline
\end{tabular}

يُزوهش نشـان داد بين نشـانهاى اختلال نارسايى توجه - فزون كنشى با

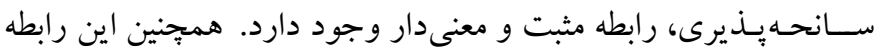
بهوسيله متغيرهاى ميانجى حسـاسـيت به ياداش و حسـاسـيت به تنبيه نيز

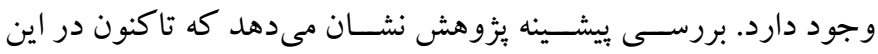

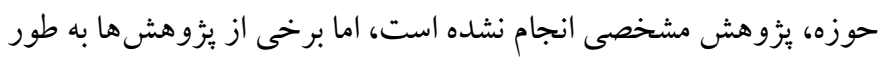

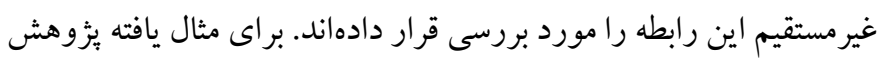
حاضـر به طور غيرمسـتقيم با يافته هاى يزوهش هاى ليو، ســو، لى و كو

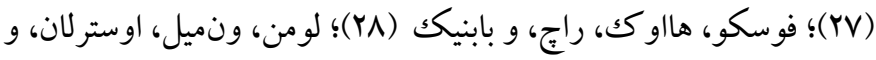

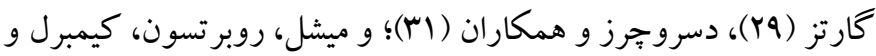

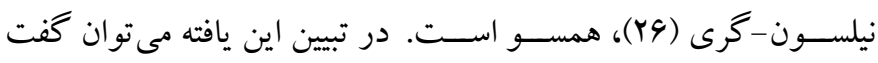

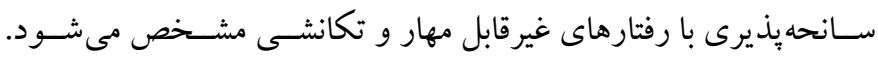

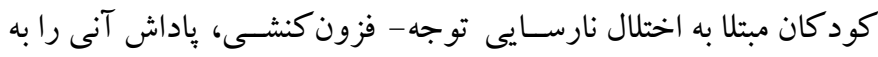

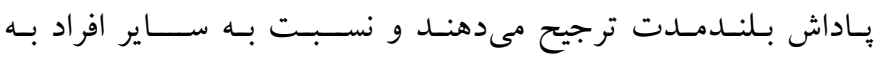

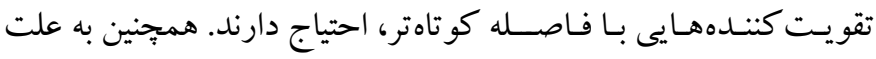
تكانشــى بودن نمى تواند رفتارهاى خود را تنظيم كنند و به بيامد رفتار

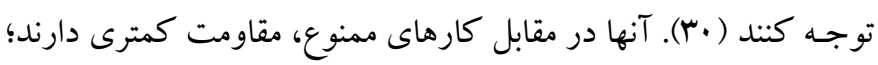

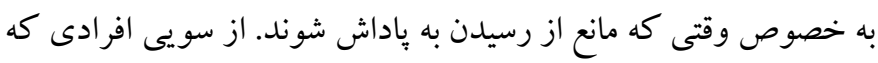

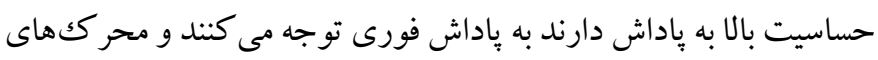

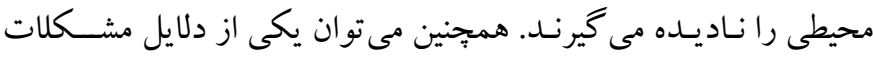

مندرجات جدول ه نشان مىدهد نارسايى توجه- فزون كنشى به طور

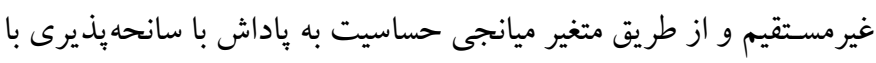

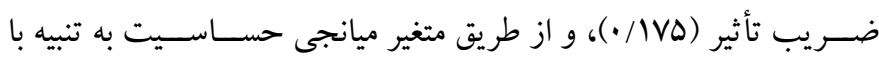

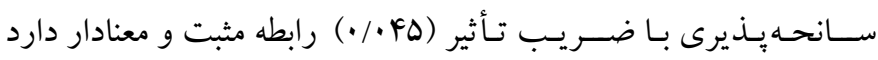

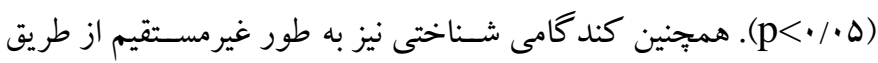

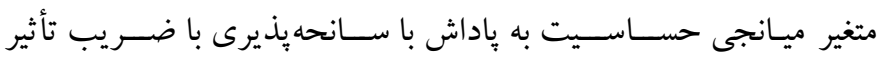

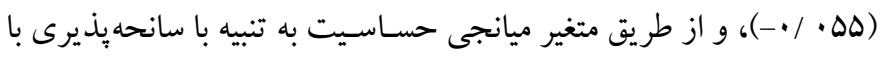

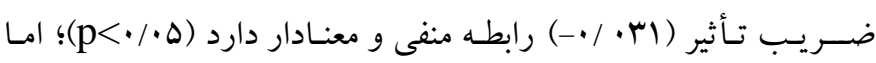
برخلاف نارسايى توجه - فزون كنشى، رابطه غيرمستقيم كند كامى شناختى ونى

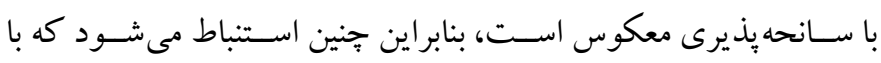

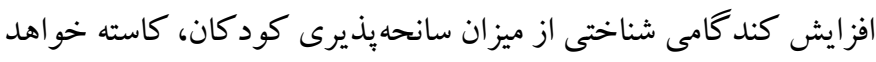

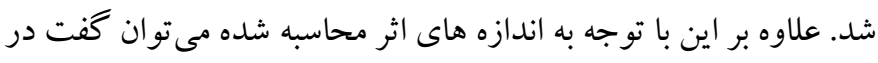

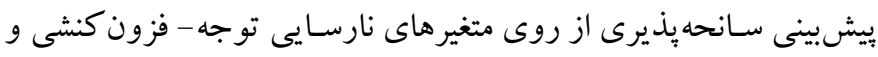

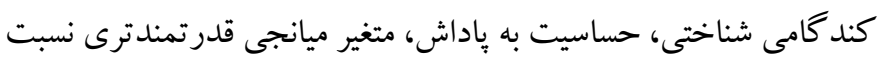
به حساسيت به تنبيه است.

\section{بحث و نتيجه كيرى}

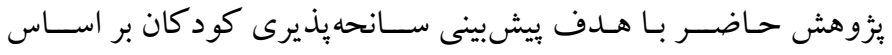

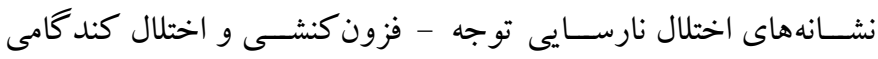

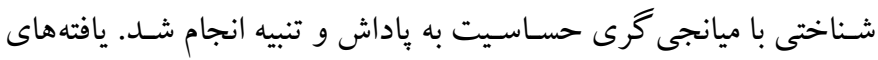


فعاليت بالاى سـيستم حسـاسيت به تنبيه مثل سـيستم مقايسـهـ عمل عمل

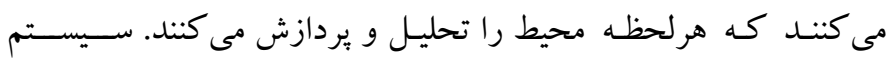

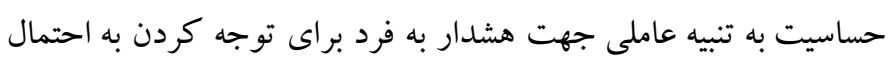

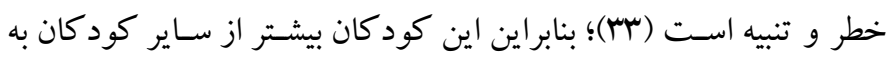

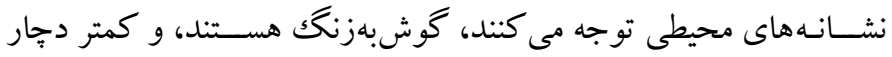

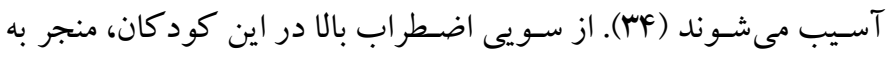

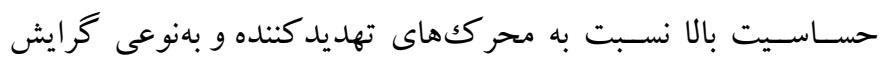

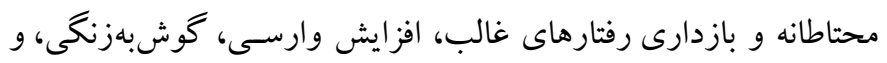

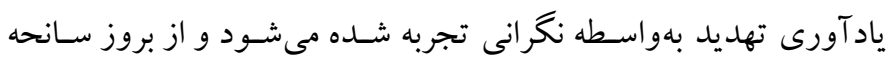

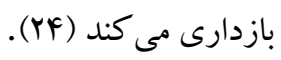
بزّوهش حاضر همانند هر بزّوهش ديخرى داراى محدوديتهايى بود

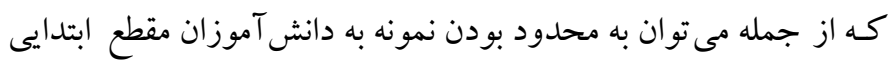

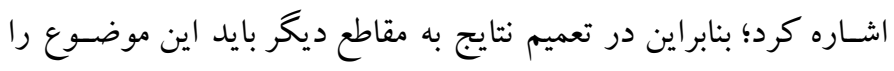

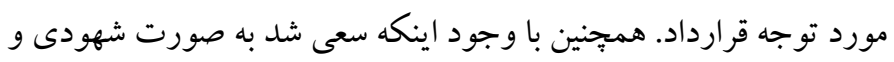

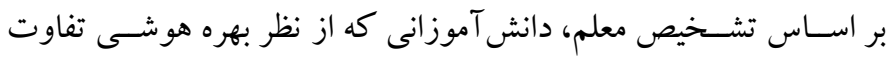

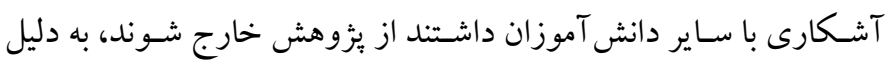

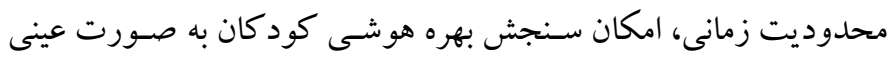

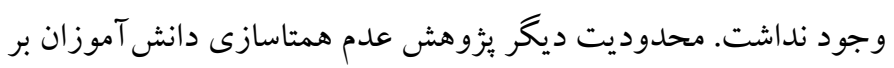

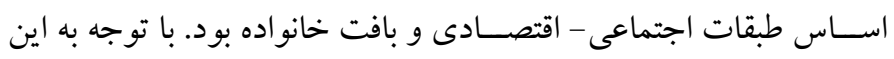

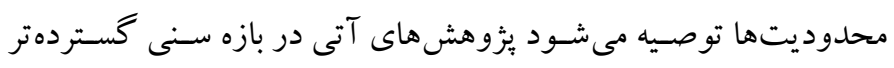

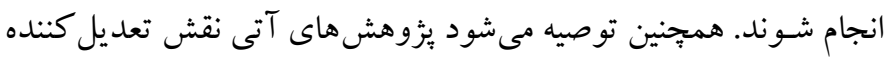

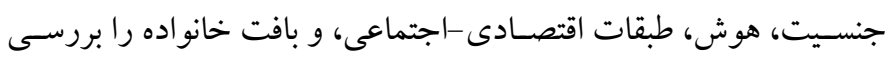
كرده يا در صورت امكان گروهها را از نظر اين متغيرها، همتاسازى كنند.

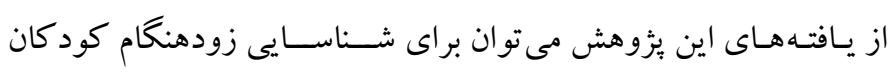

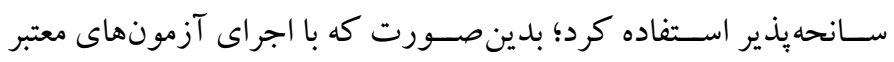

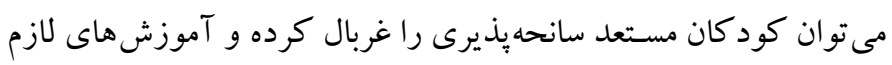

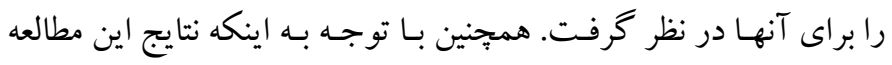

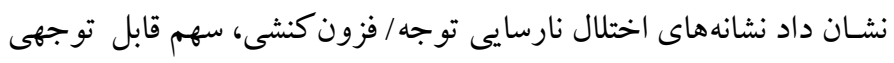

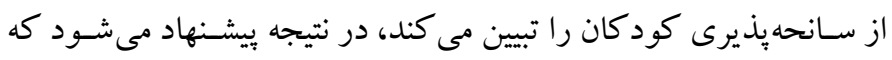

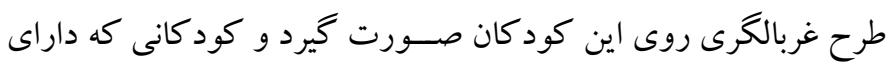

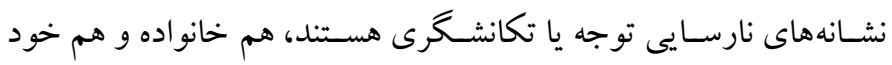

توجهى اين افراد را وابسته به اين موضوع دانست كه اكر آن كار باداشى

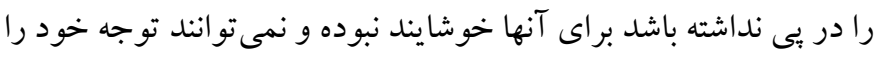

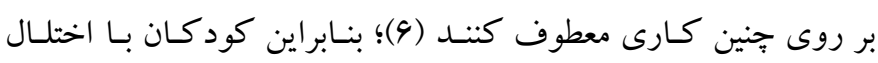

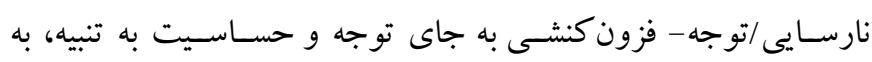

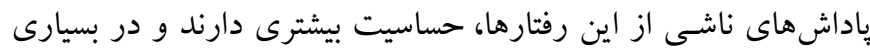

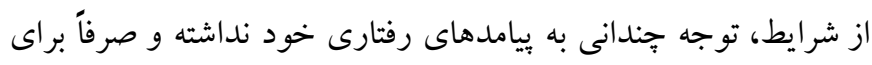

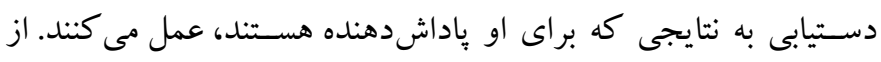

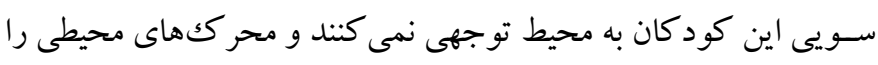

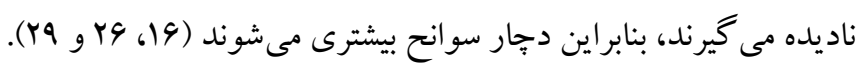

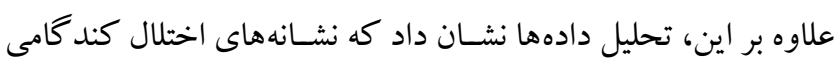
شـناختى با سـانحه يذيرى رابطه منفى و معنى دار دارد. همجينين اين ارتباط به وسـيله متغير هاى ميانجى حسـاسـيت به باداش و حسـاسـيت به بن تنبيه نيز

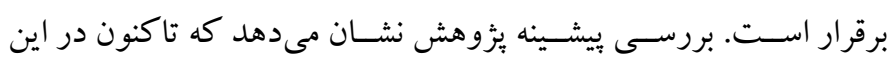

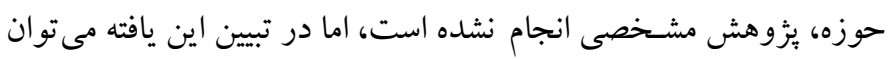

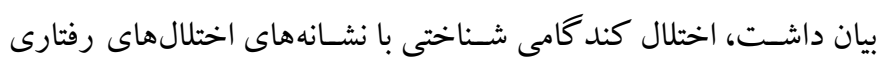

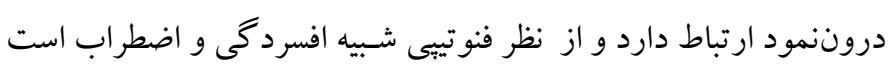
(IF)

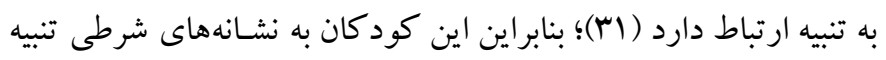

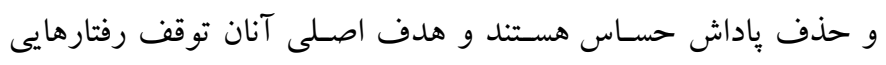

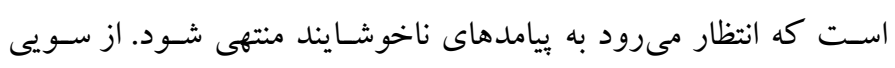

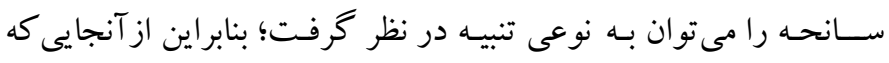

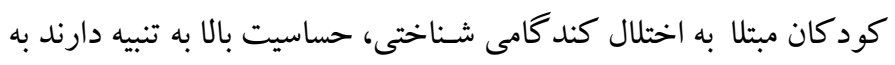

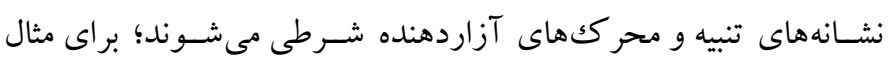

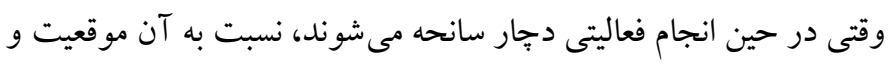

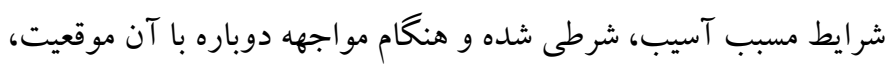

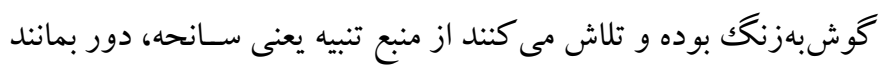

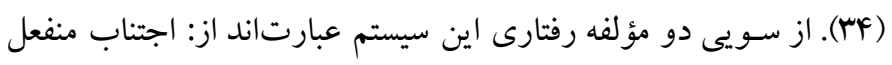

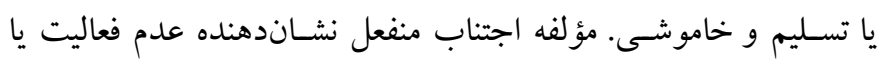

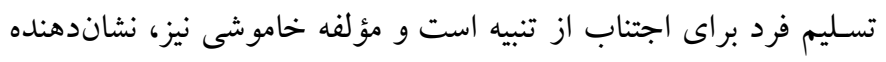

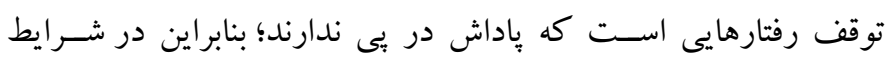

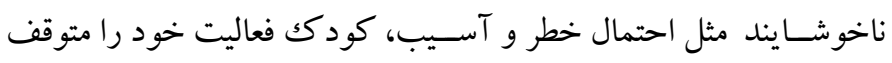

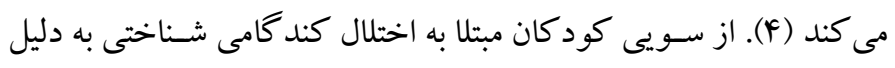


شـده است. بدينوسيله از اداره آموزش و بِرورش كل شهرستان تبريز، آموزش

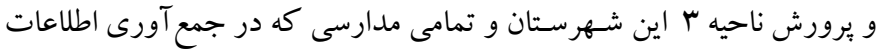
براى اجراى يزوهش همكارى كردند، تشكر و قدردانى مىشود.

تضاد منافع: يادآور مىشود اين يزوهش براى نويسند گان هيج گونه تضاد منافعى نداشته است.
كود كـان نسـبت به اين مشــكل آكاه شــوند و آموزشهايى در جهت بيشخيرى از ايجاد سانحه به والدين و كود كان ارائه شود. تشكر و قدردانى: اين مطالعه بهصورت مستقل اجراشده است و مجوز اجراى

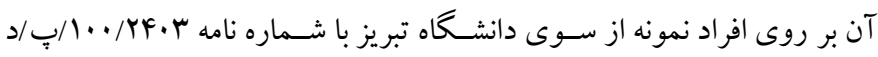
مورخ

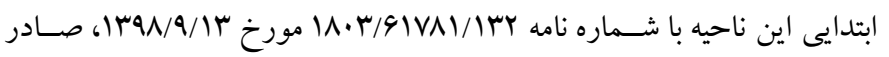




\section{References}

1. Hardelid P, Davey J, Dattani N, Gilbert R. Child deaths due to injury in the four UK countries: A time trends study from 1980 to 2010. PLoS One. 2013; 8(7): e68323. [Link]

2. Helton JJ, Weaver NL. Unintentional child injury in child welfare placements. Child Abuse Negl. 2020; 99: 104231. [Link]

3. World Health Organization. International classification of functioning, disability, and health: Children \& youth version: ICF-CY. World Health Organization; 2007, pp: 188-189. [Link]

4. Ghirardi L, Larsson H, Chang Z, Chen Q, Quinn PD, Hur K, et al. Attention-deficit/hyperactivity disorder medication and unintentional injuries in children and adolescents. J Am Acad Child Adolesc Psychiatry. 2019 Jul 11; In Press. [Link]

5. Prasad V, West J, Sayal K, Kendrick D. Injury among children and young people with and without attentiondeficit hyperactivity disorder in the community: The risk of fractures, thermal injuries, and poisonings. Child Care Health Dev. 2018; 44(6): 871-878. [Link]

6. Barton BK, Schwebel DC. The roles of age, gender, inhibitory control, and parental supervision in children's pedestrian safety. J Pediatr Psychol. 2007; 32(5): 517-526. [Link]

7. Morrongiello BA, Ondejko L, Littlejohn A. Understanding toddlers' in-home injuries: I. Context, correlates, and determinants. J Pediatr Psychol. 2004; 29(6): 415-431. [Link]

8. Schwebel DC, Binder SC, Sales JM, Plumert JM. Is there a link between children's motor abilities and unintentional injuries? J Safety Res. 2003; 34(2): 135141. [Link]

9. Pulkkinen L. Behavioral precursors to accidents and resulting physical impairment. Child Dev. 1995; 66(6): 1660-1679. [Link]

10. Wafer CD. A comparative study of parental perceptions of risk-taking in children [Doctoral dissertation]. [San Diego, United States]: Faculty of the California School of Professional Psychology, Alliant International University; 2019, pp: 1-15. [Link]

11. Hurtig $\mathrm{T}$, Ebeling $\mathrm{H}$, Jokelainen J, KoivumaaHonkanen H, Taanila A. The association between hospital-treated injuries and adhd symptoms in childhood and adolescence: A follow-up study in the northern Finland birth cohort 1986. J Atten Disord. 2016; 20(1): 3-10. [Link]
12. Eisenberg N, Spinrad TL. Emotion-related regulation: sharpening the definition. Child Dev. 2004; 75(2): 334-339. [Link]

13. Schwebel DC, Gaines J. Pediatric unintentional injury: Behavioral risk factors and implications for prevention. J Dev Behav Pediatr. 2007; 28(3): 245254. [Link]

14. Barkley RA. Sluggish cognitive tempo (concentration deficit disorder?): Current status, future directions, and a plea to change the name. J Abnorm Child Psychol. 2014; 42: 117-125. [Link]

15. Becker SP, Marshall SA, McBurnett K. Sluggish cognitive tempo in abnormal child psychology: An historical overview and introduction to the special section. J Abnorm Child Psychol. 2014; 42(1): 1-6. [Link]

16. Becker SP. "For some reason I find it hard to work quickly": Introduction to the special issue on sluggish cognitive tempo. J Atten Disord. 2017; 21(8): 615622. [Link]

17. Tamm L, Brenner SB, Bamberger ME, Becker SP. Are sluggish cognitive tempo symptoms associated with executive functioning in preschoolers? Child Neuropsychol. 2018; 24(1): 82-105. [Link]

18. Jarrett MA, Rapport HF, Rondon AT, Becker SP. ADHD dimensions and sluggish cognitive tempo symptoms in relation to self-report and laboratory measures of neuropsychological functioning in college students. J Atten Disord. 2017; 21(8): 673683. [Link]

19. Penny AM, Waschbusch DA, Klein RM, Corkum P, Eskes G. Developing a measure of sluggish cognitive tempo for children: Content validity, factor structure, and reliability. Psychol Assess. 2009; 21(3): 380-399. [Link]

20. Plourde V. Commentary on "The neurocognitive nature of children with ADHD comorbid sluggish cognitive tempo: Might SCT be a disorder of vigilance?" Psychiatry Res. 2019; 279: 370-371. [Link]

21. Fredrick JW, Kofler MJ, Jarrett MA, Burns GL, Luebbe AM, Garner AA, et al. Sluggish cognitive tempo and ADHD symptoms in relation to taskunrelated thought: Examining unique links with mindwandering and rumination. J Psychiatr Res. 2020; 123 : 95-101. [Link]

22. Marshall SA, Evans SW, Eiraldi RB, Becker SP, Power TJ. Social and academic impairment in youth with ADHD, predominately inattentive type and sluggish cognitive tempo. J Abnorm Child Psychol. 2014; 42(1): 77-90. [Link] 
23. Becker SP, Langberg JM. Sluggish cognitive tempo among young adolescents with ADHD: Relations to mental health, academic, and social functioning. J Atten Disord. 2013; 17(8): 681-689. [Link]

24. Bauermeister JJ, Barkley RA, Bauermeister JA, Martínez JV, McBurnett K. Validity of the sluggish cognitive tempo, inattention, and hyperactivity symptom dimensions: Neuropsychological and psychosocial correlates. J Abnorm Child Psychol. 2012; 40(5): 683-697. [Link]

25. Azad Falah P, Dadsetan P. Brain / behavioral systems: Biological structures of personality. Modarres Human Sciences. 2000; 4(1): 63-82. [Persian]. [Link]

26. Mitchell JT, Robertson CD, Kimbrel NA, NelsonGray RO. An evaluation of behavioral approach in adults with ADHD. J Psychopathol Behav Assess. 2011; 33(4): 430. [Link]

27. Liu T-L, Su C-H, Lee J-I, Ko C-H. The reinforcement sensitivity of male adults with attentiondeficit/hyperactivity disorder: The association with internet addiction. Taiwanese Journal of Psychiatry. 2019; 33(1): 39-44. [Link]

28. Fosco WD, Hawk LW, Rosch KS, Bubnik MG. Evaluating cognitive and motivational accounts of greater reinforcement effects among children with attention-deficit/hyperactivity disorder. Behav Brain Funct. 2015; 11: 20. [Link]

29. Luman M, van Meel CS, Oosterlaan J, Geurts HM. Reward and punishment sensitivity in children with ADHD: Validating the sensitivity to punishment and sensitivity to reward questionnaire for children (SPSRQ-C). J Abnorm Child Psychol. 2012; 40(1): 145-157. [Link]

30. Chess S, Hassibi M. Principles and practice of child psychiatry. New York: Springer Science \& Business Media; 2013: pp: 45-48. [Link]

31. Desrochers SS, Lesko E, Magalong VM, Balsam PD, Nautiyal KM. A role for reward sensitivity in the serotonergic modulation of impulsivity. bioRxivorg. 2020; 2020.01.17.910778. [Link]

32. Lee S, Burns GL, Snell J, McBurnett K. Validity of the sluggish cognitive tempo symptom dimension in children: Sluggish cognitive tempo and ADHDinattention as distinct symptom dimensions. J Abnorm Child Psychol. 2014; 42(1): 7-19. [Link]
33. Colder CR, Trucco EM, Lopez HI, Hawk LW, Read JP, Lengua LJ, et al. Revised reinforcement sensitivity theory and laboratory assessment of BIS and BAS in children. J Res Pers. 2011; 45(2): 198-207. [Link]

34. Corr PJ. Reinforcement sensitivity theory of personality questionnaires: Structural survey with recommendations. Pers Individ Dif. 2016; 89: 60-64. [Link]

35. Kline RB. Principles and practice of structural equation modeling. Fourth Edition. Guilford Publications; 2015, pp: 74-77. [Link]

36. Peterson L, Saldana L, Heiblum N. Quantifying tissue damage from childhood injury: The minor injury severity scale. J Pediatr Psychol. 1996; 21(2): 251267. [Link]

37. Mohammadi E. Predicting the accident proneness using sensitivity to reward and sensitivity to punishment with the meditative role of impulsivity and inattention factors [Thesis for Master of Science]. [Tabriz, Iran]: Faculty of Educational Science and Psychology, Tabriz University; 2019, pp: 39-40. [Persian].

38. Swanson JM, Nolan WJ, Pelham WE. A parentteacher rating scale for operationalizing DSM III symptoms of attention deficit disorder [Unpublished manuscript]. [California, United States]: University of California, Irvine; 1981, pp: 454-463. [Link]

39. Bussing R, Fernandez M, Harwood M, Hou W, Garvan CW, Swanson JM, et al. Parent and teacher snap-iv ratings of attention deficit/hyperactivity disorder symptoms: Psychometric properties and normative ratings from a school district sample. Assessment. 2008; 15(3): 317-328. [Link]

40. Sadrosadat SJ, Houshyari Z, Zamani R, Sadrosadat L. Determinatio of psychometrics index of SNAP-IV rating scale in Parents execution. Archives of Rehabilitation. 2008; 8(4): 59-65. [Persian]. [Link]

41. Lejuez CW, Read JP, Kahler CW, Richards JB, Ramsey SE, Stuart GL, et al. Evaluation of a behavioral measure of risk taking: The balloon analogue risk task (BART). J Exp Psychol Appl. 2002; 8(2): 75-84. [Link]

42. Ekhtiari H, Janati A, Moghimi A, Behzadi A. The Farsi version of the balloon analogue risk task: An instrument for the assessment of riskful-decision making. Advances in Cognitive Science. 2003; 4(4): 9-11. [Persian]. [Link] 